\title{
Bilateral Oophorectomy
}

National Cancer Institute

\section{Source}

National Cancer Institute. Bilateral Oophorectomy. NCI Thesaurus. Code C51590.

Surgery to remove both ovaries. 